\title{
Temporal differences of onset between primary skin lesions and regional lymph node lesions for tularemia in Japan: a clinicopathologic and immunohistochemical study of 19 skin cases and 54 lymph node cases
}

\author{
Shigeyuki Asano $\cdot$ Kikuo Mori • Kazuki Yamazaki • \\ Tetsutaro Sata • Takayuki Kanno • Yuko Sato • \\ Masaru Kojima • Hiromi Fujita • Yasushi Akaike • \\ Haruki Wakasa
}

Received: 1 March 2012 /Revised: 17 April 2012 /Accepted: 2 May 2012 /Published online: 17 May 2012

(C) The Author(s) 2012. This article is published with open access at Springerlink.com

\begin{abstract}
For tularemia, a zoonosis caused by the gramnegative coccobacillus Francisella tularensis, research of the relation between skin lesions and lymph node lesions has not been reported in the literature. This report describes skin lesions and lymph node lesions and their mutual relation over time for tularemia in Japan. Around the second day after infection (DAI), a subcutaneous abscess was observed (abscess form). Hand and finger skin ulcers formed during the second to the fourth week. Subcutaneous and dermal granulomas were observed with adjacent monocytoid B
\end{abstract}

S. Asano $(\bowtie) \cdot$ K. Mori $\cdot$ K. Yamazaki

Department of Pathology, Iwaki Kyoritsu General Hospital, 16 Kusehara, Mimaya-machi, Uchigo,

Iwaki 973-8555, Japan

e-mail: patho.asano@gmail.com

T. Sata $\cdot$ T. Kanno $\cdot$ Y. Sato

Department of Pathology, National Institute of Infectious Diseases,

Tokyo, Japan

M. Kojima

Department of Pathology, Dokkyo University School of Medicine,

Tochigi, Japan

\section{H. Fujita}

Ohara Laboratory Institute,

Fukushima, Japan

Y. Akaike

Department of Pathology, Shimotsuga General Hospital,

Tochigi, Japan

H. Wakasa

Tohoku Bunka Gakuen University,

Sendai, Japan lymphocytes (MBLs) (abscess-granulomatous form). From the sixth week, large granulomas with central homogeneous lesions emerged diffusely (granulomatous form). On 2-14 DAI, $F$. tularensis antigen in skin lesions was detected in abscesses. During 7-12 DAI, abscesses with adjacent MBLs appeared without epithelioid granuloma (abscess form) in regional lymph nodes. During the second to fifth week, granulomas appeared with necrosis (abscess-granulomatous form). After the sixth week, large granulomas with a central homogeneous lesion (granulomatous form) appeared. $F$. tularensis antigen in lymph node lesions was observed in the abscess on 7-92 DAI. Apparently, F. tularensis penetrates the finger skin immediately after contact with infected hares. Subsequently, the primary lesion gradually transfers from skin to regional lymph nodes. The regional lymph node lesions induced by skin lesion are designated as dermatopathic lymphadenopathy. This study revealed temporal differences of onset among the skin and lymph node lesions.

Keywords Tularemia $\cdot$ Primary skin lesions $\cdot$ Regional lymph node lesions $\cdot$ Temporal differences of onset

\section{Introduction}

Tularemia is a zoonosis caused by the gram-negative coccobacillus Francisella tularensis, the etiologic agent of the disease [1-5]. Soken Honma, a physician in Mito, Ibaraki Prefecture, Japan, described tularemia as "hare meat poisoning" (1837) [3] in the oldest report of the disease. In California, USA, McCoy (1911) [6] reported a plague-like disease affecting squirrels. 
Ohara and Kitamura [3, 7] confirmed its transmissibility to humans. F. tularensis was named after Francis and the town in which the bacterium was isolated: Tulare, California, USA (1921) [6]. In Japan, Hachiro Ohara established the Ohara Institute in Fukushima for the active study of tularemia (1925) [3]. Japanese armed forces (1932-1945) and the U.S. Army (1950-1960) undertook studies to develop tularemia bacteria for use as a biological weapon $[1,8,9]$.

After bioterrorism with anthrax in 2001, the Centers for Disease Control (CDC) classified tularemia into the most dangerous pathogen group, category A, along with smallpox and anthrax [10]. Thereafter, cases of tularemia have been reported worldwide [2, 11, 12], but it has become an exceedingly rare disease in Japan. Although the incidence of this disease has decreased, its details must be reviewed because of its potential for use in acts of bioterrorism [1, $8,10,13]$ and because of the danger it presents as an infectious disease transmitted by animals $[1,3,7]$.

Research of lymph node lesions [7] has been more common for this disease, but skin lesions and the relation between primary skin lesions and lymph node lesions has not described in the literature. This report of cases in Japan describes primary skin lesions and lymph node lesions and their mutual relation over time for tularemia in terms of clinicopathology and immunohistochemistry.

\section{Materials and methods}

Between 1950 and 1965, data of 19 skin cases and 54 lymph node cases were collected at the Ohara Laboratory Institute, Fukushima Japan. All patients files reserved at the Institute were used for this research. These files contained clinical data including symptoms, intimate contact day from infected hares, onset day and biopsy day for each patient. In addition, laboratory examinations such as serum agglutinin and skin test against $F$. tularensis showed positive.

Sections cut from $10 \%$ formalin-fixed paraffinembedded skin and lymph node samples were stained with hematoxylin-eosin (HE), Giemsa, periodic acid-Schiff (PAS), and Watanabe's silver impregnation.

For immunohistochemical examination, formalin-fixed tissue sections (4- $\mu \mathrm{m}$ thick) were deparaffinized in xylene and redehydrated in graded alcohols and distilled water. All tissue sections were incubated in $0.01 \mathrm{M}$ citrate buffer $(\mathrm{pH} 6.0)$ (Koso Chemical Co., Ltd., Tokyo, Japan) using standard microwave or autoclave heating technique for 15, $20 \mathrm{~min}$, respectively. Furthermore, immunohistochemical examination of deparaffinized sections was performed using an automated stainer (Ventana Medical Systems Inc., Arizona, USA) according to the manufacturer's instructions. Then, they were mounted with Malinol mounting (Muto Pure Chemicals Co. Ltd., Tokyo, Japan).
The panel of antibodies against CD 3 (Roche Diagnostics Corp., Ventana Medical Systems Inc.), CD 4, CD10 (Nichirei Corp., Tokyo Japan), CD 5, CD 8, CD 20, CD 30, CD 68 (all Dako, Carpinteria, Ca, USA), CD 83 (Novocastra Laboratories Ltd., U.K.), CD 163 (Lab Vision Corp., USA), CD 204 (Dr. Takeya, Kumamoto, Japan), Langerin (Novocastra Laboratories Ltd.), S-100 (Dako), D2-40 (Nichirei Corp.), Fascin, HLA-DR, IgG, IgA, IgM, $\kappa, \lambda$ (all Dako), and anti-F. tularensis antibody (Dr. Hotta, NIID, Japan) were used. Sections with known reactivity to the assayed antibodies served as positive controls. Negative controls consisted of each case tissue incubated with normal mouse serum instead of the antibody against $F$. tularensis (Table 1).

\section{Results}

\section{Clinical findings}

Clinical features of the skin lesions (19 cases) and lymph node lesions (54 cases) are presented in Tables 2 and 3 and almost all patients had visited the doctor for common coldlike symptoms such as a sudden high fever $\left(38-40^{\circ} \mathrm{C}\right)$ with chill, headache, back pain, cough, and sore throat. Most patients were male agricultural workers. Almost all patients had been infected during skinning of hares and during cooking of infected hare meat. Skin lesions and lymphadenopathy mainly included finger skin and subcutaneous lesions and regional axillary and elbow lymph nodes, respectively. There were no fatal cases.

\section{Pathological findings}

\section{Skin lesion}

In the early phase (1-8 days after infection, DAI), no ulceration was found. Many inflammation-related cells such as lymphocytes and plasma cells were observed, along with cell debris and necrosis without neutrophils in deeper dermis and subcutaneous regions under the superficial dermis (abscess form) (Fig. 1a). F. tularensis antigens were detected mainly in abscess and necrotic areas (Fig. 1b). Many S-100+, CD68+, CD83+, Fascin+, and CD163+ cells were found in dilated lymph vessels of dermal papillae. Furthermore, irregularly shaped abscesses and many S-100+ and Langerin+ dendritic cells were apparent in dilated lymph vessels around abscess and necrotic subcutaneous sites. Mainly CD20+ B cells are scattered near the abscess.

In the later phase, 14-20 DAI, ulcers appear (Figs. 1c, d). Marked dilated lymph vessels are apparent at the bottom of ulcers and dermal papillae where lymphocytes, dendritic cells, and apoptotic cells were phagocytized by macrophages 
Table 1 Antibodies used in this immunohistochemical study

\begin{tabular}{|c|c|c|c|c|c|c|}
\hline Antibody & Clone & Specificity & Source & Clonality & Retrieval & Dilution \\
\hline CD3 & $2 \mathrm{GV} 6$ & $\mathrm{~T}$ cells & Roche & M & Mic & $1: 1$ \\
\hline CD4 & $1 \mathrm{~F} 6$ & Helper/inducer T cells & Nichirei & M & Mic & $1: 1$ \\
\hline CD5 & CD5/5456 & $\mathrm{T}$ cells & Dako & M & Mic & $1: 100$ \\
\hline $\mathrm{CD} 8$ & $\mathrm{C} 8 / 144 \mathrm{~B}$ & Cytotoxic/suppressor T cells & Dako & M & Mic & $1: 1$ \\
\hline CD10 & $56 \mathrm{C} 6$ & CALLA, Immature B cells, germinal center B cells & Nichirei & M & Mic & $1: 1$ \\
\hline $\mathrm{CD} 20$ & L26 & B cells & Dako & M & Mic & $1: 1$ \\
\hline CD30 & Ber-H2 & Activated B cells & Dako & M & Mic & $1: 100$ \\
\hline CD68 & KP1 & Macrophage, plasmacytoid T cells & Dako & M & Mic & $1: 50$ \\
\hline CD83 & $1 \mathrm{H} 4 \mathrm{~b}$ & Dendritic cells, Langerhans cells & Novo & M & Mic & $1: 20$ \\
\hline CD163 & 10D6 & Macrophage scavenger receptor & $\mathrm{Lab}$ & M & Mic & $1: 50$ \\
\hline CD204 & & Macrophage scavenger receptor & a & M & Mic & $1: 1$ \\
\hline Langerin & 12D6 & Langerhans cells & Novo & M & Mic & $1: 100$ \\
\hline S-100 & & Langerhans cells, melanocyte, Schwan cells & Dako & $\mathrm{P}$ & Non & $1: 1$ \\
\hline D2-40 & D2-40 & Lymph vessel & Nichirei & M & Mic & $1: 1$ \\
\hline Fascin & $55 \mathrm{~K}-2$ & Dendritic cells, interdigitating reticulum cells & Dako & M & Mic & $1: 50$ \\
\hline HLA-DR & TAL.1B5 & Langerhans cells, Macrophages, B cells, activated T cells & Dako & M & Mic & $1: 25$ \\
\hline $\mathrm{IgG}$ & & $\operatorname{IgG}$ & Dako & $\mathrm{P}$ & Non & $1: 1$ \\
\hline $\operatorname{IgA}$ & & $\operatorname{IgA}$ & Dako & $\mathrm{P}$ & Mic & $1: 1$ \\
\hline $\operatorname{IgM}$ & & $\operatorname{IgM}$ & Dako & $\mathrm{P}$ & Mic & $1: 1$ \\
\hline$\kappa$ & R10-21-f3 & $\kappa$ & Dako & M & Non & $1: 1$ \\
\hline$\lambda$ & $\mathrm{N} 10 / 2$ & $\lambda$ & Dako & M & Non & $1: 1$ \\
\hline F.tularensis & & F.tularensis & $\mathrm{b}$ & $\mathrm{P}$ & Auto & $1: 1$ \\
\hline
\end{tabular}

Roche Roche Diagnostics, Arizona, USA, Nichirei Nichirei, Tokyo, Japan, Dako Dako, Ca, USA, Novo Novocastra, UK, Lab Lab Vision, USA $M$ monoclonal, $P$ polyclonal, Mic microwave, Auto autoclave, Non non treated

${ }^{\mathrm{a}}$ Anti-CD204 antibody and ${ }^{\mathrm{b}}$ anti-F. tularensis antibody were supplied from Dr. Takeya and Dr. Hotta, respectively

(Fig. 1e). Subcutaneous areas show several immature granulomas with radiative patterns of epithelioid cells (abscess-granulomatous form) (Fig. 1f). Giant cells and inflammation were observed. Many S-100+, CD68+, CD163+, CD204+, Fascin+, and T cells were found in and around granulomas.

Table 2 Summary of clinical findings of skin lesions, 19 cases

\begin{tabular}{lll}
\hline Age distribution & $19-69$ & $\begin{array}{c}\text { Mean 43 years, } \\
\text { median 44 years }\end{array}$ \\
$\begin{array}{l}\text { Male:female ratio } \\
\text { Occupation }\end{array}$ & $4: 1$ & 13 cases (68\%) \\
& Farmer & 2 \\
& Charcoal maker & 4 \\
Day after infection & Other & Mean 30 days, \\
& 1-96 days & median 19 days \\
Site & Skin (hand finger) & 4 cases \\
& Subcutaneous & 14 \\
& (axillary, elbow) & 1 \\
\hline
\end{tabular}

Aggregations of monocytoid B lymphocytes (MBLs) were adjacent to the granulomas (Fig. 1g).

Dilated lymph vessels become more numerous during 28-42 DAI and similar cells to those in the previous phase appear at the bottom of the ulcer of dermis. Numerous granulomas are also observed not only in subcutaneous areas but also in superficial dermis. In addition, numerous multinucleated giant cells appear near the granulomas.

In the last phase, skin ulcers are scarred after around the sixth week. During 51-96 DAI, many irregularly shaped fused epithelioid granulomas with central homogeneous lesions are observed in subcutaneous and dermis areas (granulomatous form) (Fig. 1h). Similar cells to those in the previous phase appear in and around granulomas. Giant cells are observed occasionally at epithelioid granulomas. Aggregations of MBLs, adjacent to the granulomas, were also observed in this phase. Many S-100+, CD68+, and CD163+ cells were also observed in marked distended lymph vessels of dermal papillae.

The $F$. tularensis antigen of the skin lesion was detected only in the abscess, except with granuloma at 2-14 DAI (Fig. 2). 
Fig. 1 Skin and subcutaneous a Central necrosis and abscess (asterisk) of subcutaneous area with marginal lymphocytes (4 DAI). b Immunostaining. $F$. tularensis antigens (arrow) were detected mainly in abscesses and necrotic areas (4 DAI) (anti-F. tularensis antibody). c Skin ulcer (arrow) of the right middle finger (14 DAI). d Various sizes of granulomas (arrow) at ulcer base of dermis. e Lymphocytes, apoptotic cells, and macrophages were observed within marked distended lymph vessels (arrow) (30 DAI). (Anti-D2-40 antibody). f Epithelioid granuloma (arrow) in dermis with central necrosis (asterisk) was adjacent to CD $20+$ lymphocyte aggregation $($ bold arrow $=$ italic $)$. $\mathbf{g}$

Enlargement of $\mathbf{f}$. Many CD 20 + lymphocytes (monocytoid B lymphocytes; MBLs) aggregated near the granuloma (19 DAI). h Large irregularly shaped epithelioid granuloma with central homogeneous lesion (asterisk) in dermis. No antigen was detected in the lesion (75 DAI)
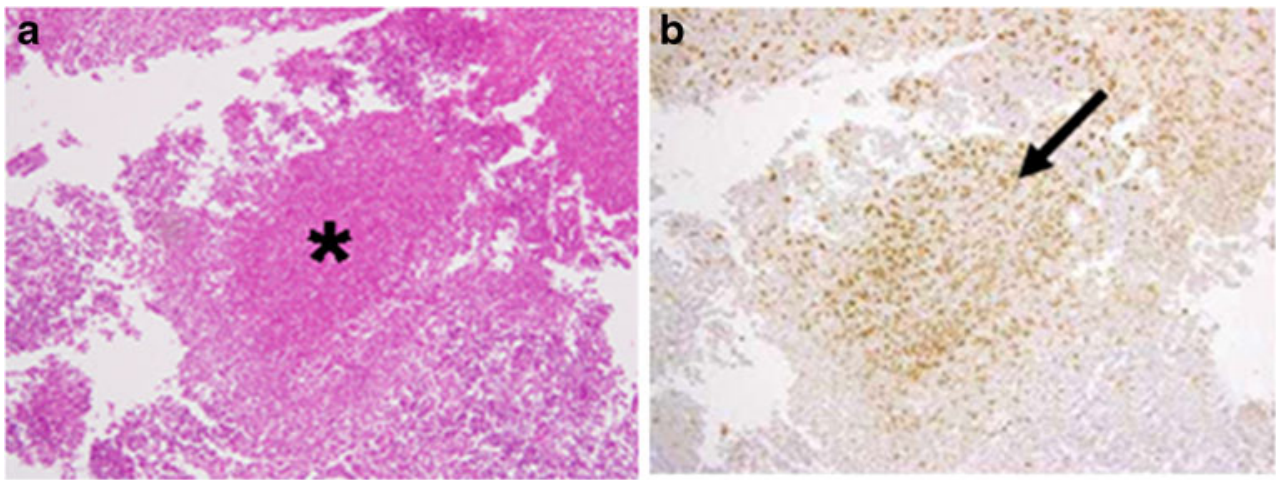

C
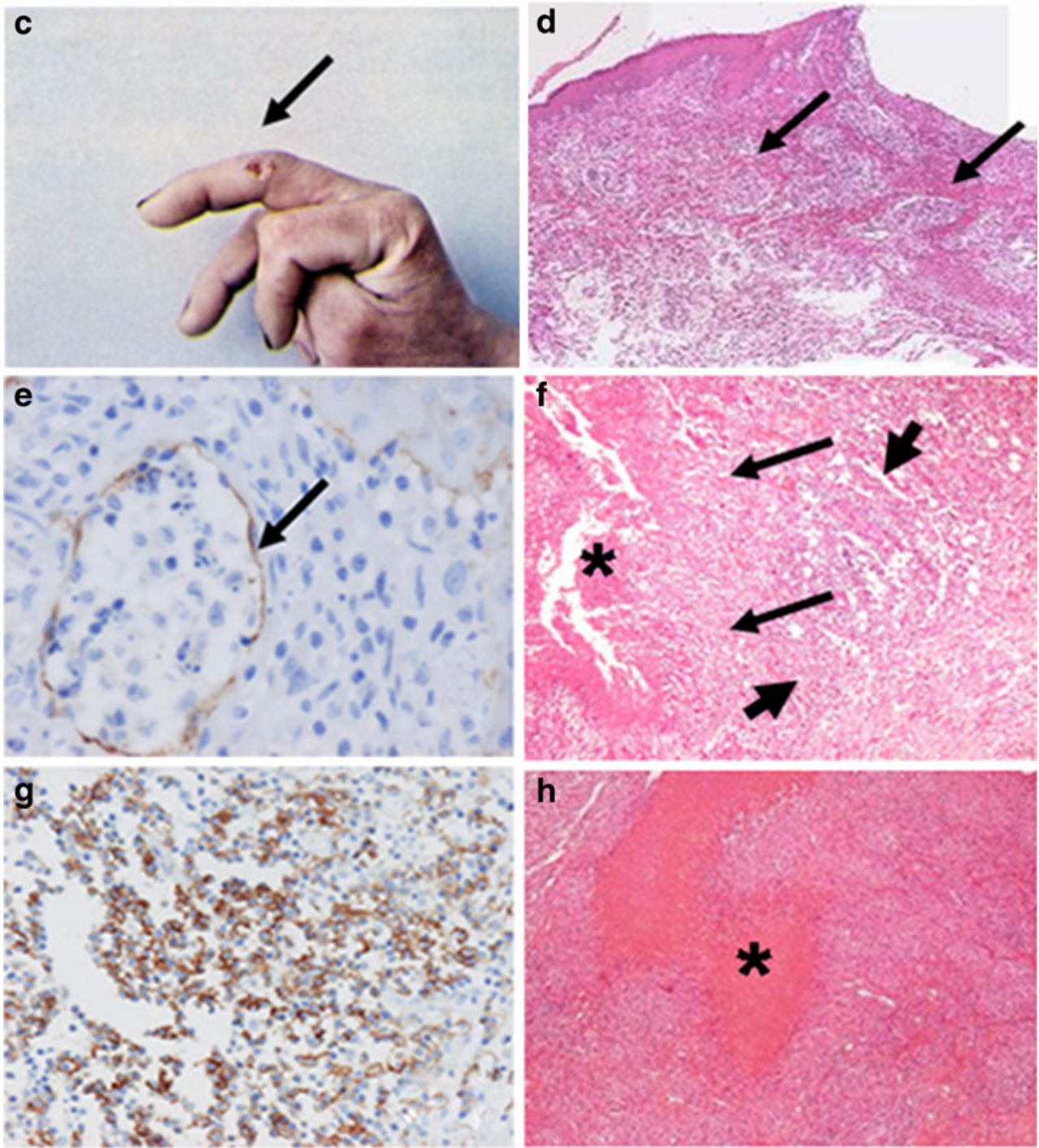

\section{Lymph node lesion}

During 7-12 DAI, sinus histiocytosis and follicular hyperplasia appeared. Small abscesses and mononuclear cells appeared (abscess form) (Fig. 3a). F. tularensis antigens were detected mainly in abscess and necrotic areas (Fig. 3b). Adjacent to abscesses, MBLs aggregation was observed. Some cases show marked periadenitis because of acute inflammation.

During the second to fifth week after infection, small epithelioid granulomas with central necrosis were apparent beneath the capsular area and medulla of lymph nodes (abscess-granulomatous form) (Figs. 3c, d). The epithelioid cells of the granulomas occasionally showed a radiative 
Table 3 Summary of clinical findings of lymphadenopathy, 54 cases

\begin{tabular}{|c|c|c|c|}
\hline Age distribution & $8-69$ & & Mean 39 years, median 37 years \\
\hline Male:female ratio & $4: 1$ & & \\
\hline \multirow[t]{4}{*}{ Occupation } & Farmer & & 40 cases $(74 \%)$ \\
\hline & Charcoal maker & & 3 \\
\hline & Carpenter & & 2 \\
\hline & $\begin{array}{l}\text { Other (teacher, woodcutter, charcoal } \\
\text { maker, hotel worker) furrier, child) }\end{array}$ & & 9 \\
\hline Day after infection & $6-133$ days & & Mean 33 days, median 24 days \\
\hline \multirow[t]{7}{*}{ Site } & Axillary $(76 \%)$ & Left & 21 \\
\hline & & Right & 21 \\
\hline & & Bilateral & 4 \\
\hline & Elbow $(7 \%)$ & Left & 1 \\
\hline & & Right & 3 \\
\hline & Mandible & & 1 \\
\hline & Unknown & & 3 \\
\hline
\end{tabular}

pattern. Many S-100+, CD68+, CD163+, CD204+, Fascin+, HLA-DR+, and T cells were found in and around granulomas.

The MBLs were adjacent to the granuloma, as in an earlier phase (Fig. 3e). Regarding lymphocyte distribution in and around granulomas, CD4/CD8 T cell ratios were 2.3, 1.1, and 2.0, respectively, at abscesses, granulomas, and outer layers of granulomas (Fig. 3f). Furthermore, numerous multinucleated giant cells are scattered in granulomatous lesions.

After the sixth week, many large granulomas with central homogeneous lesions resembling tuberculous nodes (granulomatous form) were present. They were mutually fused, forming irregularly shaped granulomas (Fig. 3g). Similar cells to those in the previous phase appear in and around granulomas. Many MBLs were observed as adjacent to granulomas, as noted for the prior phase (Fig. 3h). In addition, many multinucleated giant cells were observed in granulomatous lesions.

F. tularensis antigen was observed from 7-92 DAI in the abscess, except that with granuloma (Fig. 2).

\section{Discussion}

From their pathological study of the tularemia, Kitamura et al. [7] described lymph node and skin phenomena. According to their report, lymph node lesions are classifiable with time into three forms: abscess form, abscess-granulomatous form, and granulomatous form. Skin ulcers form in the first week and scar tissue formation is observed in the second to fifth week after onset. Healing of skin lesions might be more rapid than that of lymph nodes [7].

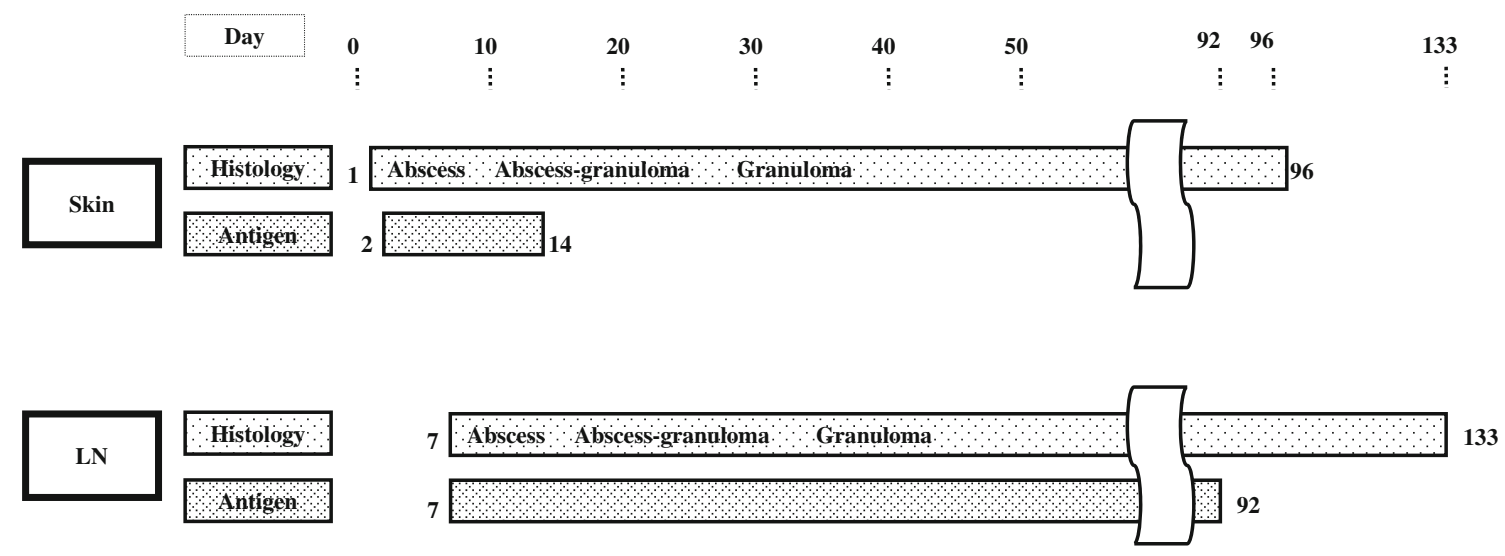

Fig. 2 Histology and F. tularensis antigen of skin and lymph node. F. tularensis antigen was detected during 2-14 DAI, and 7-92 DAI, in abscess and necrotic area of skin and lymph node, respectively. Day, days after infection (numbers of columns denote days); $L N$, lymph node; Antigen, antigen for $F$. tularensis; Histology was classified into three forms: abscess, abscess-granulomatous, and granulomatous [7] 
Fig. 3 Abscess form lymph node lesion (10 DAI). a Abscess and necrosis lesion (asterisk) without epithelioid granuloma located in the paracortex of a lymph node (10 DAI). b F. tularensis antigens (arrow) were mainly present in abscesses and necrosis lesions (asterisk) (10 DAI). (Anti-F. tularensis antibody). c

Abscess-granulomatous form lymph node lesion (14 DAI). Marked swelled axillary lymph node on the cut section. d Central abscess and necrosis lesion (asterisk) was surrounded by thick epithelioid cell granuloma (14 DAI). e CD20+ monocytoid B lymphocytes (MBLs) aggregations (arrow) were adjacent to granuloma. Asterisk, abscess and necrosis lesion (14 DAI). $\mathbf{f ~ C D} 4 / \mathrm{CD} 8$ ratio was 2.3 $\left({ }^{*} A\right), 1.1\left({ }^{*} B\right)$, and $2.0\left({ }^{*} C\right)$ in abscess-granulomatous form of lymph node. g Granulomatous form lymph node lesion (92 DAI). Large irregular granuloma with central homogeneous lesion (asterisk). Very few antigens were detected in abscesses. $\mathbf{h}$ CD20+ cells (MBLs) aggregations (arrow) were adjacent to the outer layer of epithelioid cell granuloma. Asterisk, central homogeneous lesion
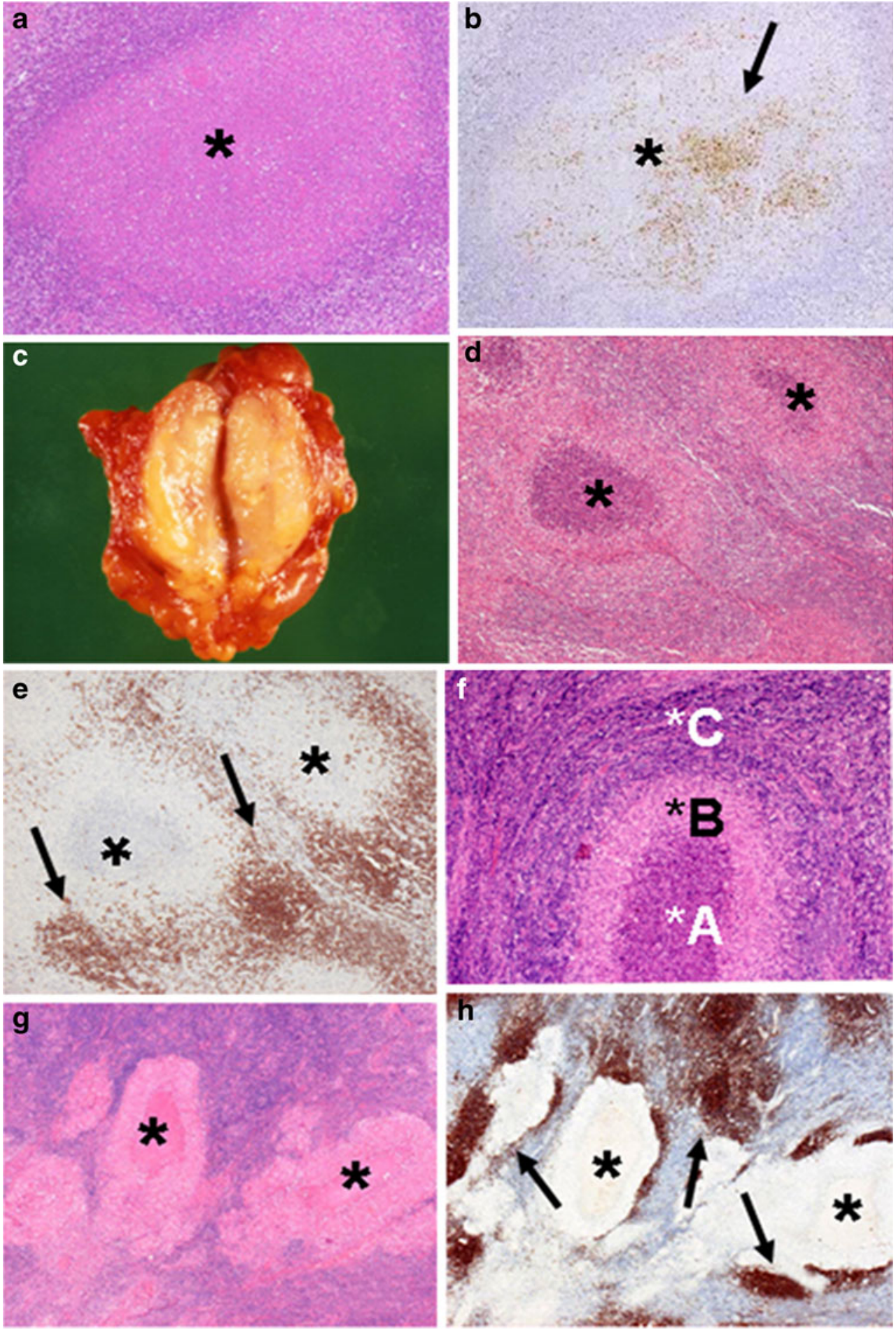

Our study revealed that the primary skin lesions, especially in subcutaneous lesions, induced by $F$. tularensis occurred from 2 DAI and that lymph node lesions developed during 7-14 DAI. The time difference of onset was apparent among these skin and lymph node cases.

Molecular biological analysis showed that DNA sequences of $F$. tularensis from the infected hare coincided with that of regional lymph node of the patient [in prepare]. It may be concluded that $F$. tularensis penetrates intact human skin after direct contact with an infected hare. Subsequently, it is transported via the skin lymphatic stream to subcutaneous regions and then to regional lymph nodes $[14,15]$. The most common skin ulcers occurred on the finger skin up to the second week after infection, and scars formed up to the sixth week in this study. Many antigen presenting cells (APCs) such as histiocytes, leukocytes, lymphocytes, and 
Langerhans cells were observed within dilated lymph vessels in the primary skin lesion. Many recruited APCs at the subcutaneous region or lymph node, contributing to production of abscesses and granuloma formation. During this period, granulomas with marked inflammation were formed at the base of the ulcer, and F. tularensis was detected only at abscesses. As described above, regional lymph node lesions induced by skin disease are designated as dermatopathic lymphadenopathy (DPL) [16]. The primary skin lesion gradually transfers from the skin to regional lymph nodes $[14,17]$.

Dermatopathic lymphadenopathy (DPL) is a commonly paracortical hyperplasia of a regional lymph node induced by chronic skin diseases such as erythroderma and mycosis fungoides. It persists even after distinct skin lesions have disappeared by the time of lymph node biopsy [16]. In general, the pathological finding of DPL is characterized by the presence of eosinophils, histiocytes, lymphoblasts, and Langerhans cells appearing as a pale area in the paracortex in the lymph node. In contrast, in tularemic lymph nodes, cells of such kinds do not appear because the primary skin lesions are acute dermatitis induced by F. tularensis [7]. Based on the discussion presented above, tularemic lymphadenopathy can be regarded as DPL of an acute type.

Secondary skin lesions on the hand, leg, and neck caused by an allergic reaction to bacteria are papular or papulovesicular eruptions that occur around 10 DAI. They might occur bilaterally, symmetrically, or as widely distributed, and can take 2 weeks to subside. Erythema nodosum and erythema multiforme are also secondary skin lesions. $F$. tularensis was also detected from erythema multiforme vesicle fluid $[18,19]$. However, secondary skin lesions do not produce ulcers as primary skin lesions do [20, 21].

Earlier reports have described that $F$. tularensis antigen was detected only in the abscesses of skin and lymph node lesions [14]. The long-lasting antigen against $F$. tularensis in the lymph nodes might contribute to the sustained presence of serum antibodies. Furthermore, CD4 $+\mathrm{T}$ cells, which affect $\mathrm{B}$ cells to stimulate antibody production, were present in greater numbers in granuloma than $\mathrm{CD} 8+\mathrm{T}$ cells were. The factors described above contributed to antibody production. However, the antigen was apt to diminish after mature granuloma formation.

In the early phase of tularemia, numerous neutrophils, monocytoid B cells (MBLs), histiocytic cells, T cells, S-100+, Langerin+, CD83+, CD163+ dendritic cells are found in lesions. An MBL cluster was occasionally observed adjacent to a microabscess from the abscess forming phase. During abscess and granuloma formation, macrophages might recruit MBLs with subsequent infiltration of neutrophils, followed by necrosis and eventual granuloma formation [22]. Furthermore, inflammatory cells such MBLs, CD68+, CD163+,
CD204+ macrophages, S-100+, Langerin+, CD83+, CD163+ dendritic cells and $\mathrm{T}$ lymphocytes can be regarded as playing an important role for granuloma formation in tularemia, as in cat scratch disease [23].

It is occasionally difficult to distinguish tularemia from tuberculosis because they have similar granulomas. Tularemia, which has clinically acute inflammation, begins with much more rapid progress than that of tuberculosis. Regarding histologic characteristics of tularemia, the epithelioid cell layer is generally thicker than that of tuberculosis, with disappearance of argyrophilic fibers in the center of the granulomas of tularemia. Moreover, the nuclei of giant cells in tularemia are fewer than in tuberculosis [7].

Recently, rapid assay for detection of $F$. tularensis in formalin-fixed paraffin-embedded lymph nodes has become available for differential diagnosis by polymerase chain reaction (PCR) $[19,24]$. As a biosecurity issue, it is necessary to design a molecular diagnosis system for $F$. tularensis to distinguish strains of subsp. holarctica, a common strain in Japan [25], from strains of other subspecies including strains of the highly virulent subsp. tularensis $[2,26]$.

Acknowledgement This study was supported in part by a grant for research on Emerging and Re-emerging Infectious Disease (H22 Shinko-Ippan-6) from the Ministry of Health, Labour, and Welfare, Japan.

The authors appreciate support of anti-CD 204 antibody from Dr. M. Takeya, Dept. of Pathology, Kumamoto University, Kumamoto, Japan, and of anti-F. tularensis antibody, from Dr. T. Hotta, Dept. of Veterinary Science, National Institute of Infectious Diseases, Tokyo, Japan.

Conflict of interest We declare that we have no conflict of interest.

Open Access This article is distributed under the terms of the Creative Commons Attribution License which permits any use, distribution, and reproduction in any medium, provided the original author(s) and the source are credited.

\section{References}

1. Denis DT, Inglesby TV, Henderson DA et al (2001) Tularemia as a biological weapon. Medical and public health management. JAMA 285:2763-2773

2. Johansson A, Ibrahim A, Goeransson I et al (2000) Evaluation of PCR-based methods for discrimination of Francisella species and development of a specific PCR that distinguished two major subspecies of Francisella tularensis. J Clin Microbiol 38:4180-4185

3. Ohara S, Ichikawa K (1962) The distribution of Yato-byo and its clinical observations. Ohara nenpou (in Japanese) 11:1-22

4. Olsufjev NG, Meschcheryakova IS (1983) Subspecific taxonomy of Francisella tularensis. Int J Syst Bacteriol 33:872-874

5. Vogler AJ, Birdsell D, Price LB et al (2009) Phylogeography of $F$. tularensis: global expansion of a highly fit clone. J Bacterio 191:2472-2484

6. Francis E (1925) Tularemia. JAMA 84:1243-1250 
7. Kitamura S, Fukuda M, Takeda H et al (1956) Pathology of tularemia. Acta Pathol Jap 6:719-764

8. Christopher GW, Cieslak TJ, Pavlin JA et al (1997) Biological warfare: a histological perspective. JAMA 278:412-418

9. Harris S (1992) Japanese biological warfare research on humans: a case study of microbiology and ethics. Ann N Y Acad Sci 666:21-52

10. Inglesby TV, O'Toole T, Henderson DA et al (2002) Anthrax as a biological weapon: updated recommendations for management. JAMA 287:2236-2252

11. Dahlstrand S, Ringetz O, Zetterberg B (1971) Airborne tularemia in Sweden. Scand J Infect Dis 3:7-16

12. Syrjälä H, Kujara P, Salminen A (1985) Airborne transmission of tularemia in farmers. Scand J Infect Dis 17:371-375

13. Kuroda M, Serizawa M, Okutani A et al (2010) Genome-wide single nucleotide polymorphism typing method for identification of Bacillus anthracis species and strains among B. cereus group species. J Clin Microbiol 48:2821-2829

14. Guarner J, Gree PW, Bartlett J et al (1999) Immunohistochemical detection of Francisella tularensis in formalin-fixed paraffin- embedded tissue. Appl Immunohistochem Mol Morphol 7:122-126

15. Ryan TJ, Mortimer PS, Jones RL (1986) Lymphatics of the skin (neglected but important). Inter J Dermatol 25:411-419

16. Asano S, Muramatsu T, Kanno H et al (1987) Dermatopathic lymphadenopathy-electronmicroscopic, enzyme-histochemical and immunohistochemical study. Acta Pathol Jap 37:887-900

17. Tärnvik A, Berglund L (2003) Tularaemia. Eur Respir J 21:361-373

18. Foshay L (1940) Tularemia: a summary of certain aspects of the disease including methods for early diagnosis and the results of serum treatment in 600 patients. Medicine 19:1-83
19. Golovliov I, Ericsson M, Sandström G et al (1997) Identification of proteins of Francisella tularensis induced during growth in macrophages and cloning of the gene encoding a prominently induced 23-kilodalton protein. Infect Immun 65:2183-2189

20. Ohara S, Hoshishima K (1957) Diagnosis of Yato-byo (Ohara disease, tularemia in Japan). Fukushima J Med Sci 4:51-61

21. Syrjälä H, Karvonen J, Salminen A (1984) Skin manifestations of tularemia: a study of 88 cases in northern Finland during 16 years (1967-1983). Acta Derm Venereol 64:513-516

22. Chang KL, Arber DA, Gaal KK et al (2006) Lymph nodes and spleen. In: Silverberg SG, DeLellis RA, Frable WJ et al (eds) Principles and practice of surgical pathology and cytopathology, 4th edn. Churchill Livingstone, Philadelphia, pp $507-608$

23. Kojima M, Nakamura S, Kurabayashi Y et al (1995) Suppurative lesions without prominent epithelioid cell response in abscessforming granulomatous lymphadenitis. Path Res Pract 191:1072-1077

24. Versage JL, Severin DDM, Chu MC et al (2003) Development of a multitarget real-time TaqMan PCR assay for enhanced detection of Francisella tularensis in complex specimens. J Clin Microbiol 41:5492-5499

25. Kuroda M, Sekizawa T, Shinya F et al (2012) Detection of a possible bioterrorism agent, Francisella sp., in a clinical specimen by use of next-generation direct DNA sequencing. J Clin Microbiol 50:1810-1812

26. Byström M, Böchen S, Magnusson A et al (2005) Tularemia in Denmark: identification of a Francisella tularensis subsp. holarctica strain by real-time PCR and high-resolution typing by multiple-locus variable-number tandem repeat analysis. J Clin Microbiol 43:5355-5358 